\title{
Sentinel lymph node biopsy in T1/T2 squamous cell carcinomas of the tongue: A prospective study
}

\author{
KEYVAN SAGHEB ${ }^{1}$, KAWE SAGHEB ${ }^{1}$, ROMAN RAHIMI-NEDJAT ${ }^{1}$, \\ KATHY TAYLOR $^{2}$, BILAL AL-NAWAS ${ }^{1}$ and CHRISTIAN WALTER ${ }^{1}$ \\ ${ }^{1}$ Department of Oral and Maxillofacial Surgery-Plastic Surgery; ${ }^{2}$ Institute of Medical Biostatistics, \\ Epidemiology and Informatics, University Medical Centre, Johannes Gutenberg-University of Mainz, Mainz 55131, Germany
}

Received November 16, 2014; Accepted September 25, 2015

DOI: $10.3892 / \mathrm{ol} .2015 .3933$

\begin{abstract}
Commonly used staging procedures often cannot predict the absence of cervical metastases (CM) in squamous cell carcinomas (SCCs) of the oral cavity. Due to the high incidence of occult CM in numerous NO cases in the clinic, an elective neck dissection (ND) is performed. The sentinel lymph node biopsy (SNB) is a common concept in the modern surgical therapy of malignancies. The present study evaluates the applicability of this concept for T1/T2-SCC of the tongue. In a prospective clinical study, 10 consecutive patients with T1/T2-SCC of the tongue and cN0 necks, were enrolled. Following sentinel lymph node (SLN) scintigraphy, all patients underwent SNB with a $\gamma$-probe and a subsequent ND. SNB specimens were compared with histopathological assessments of surgical specimens from the ND. A total of 5 female and 5 male patients (mean age, 52 years; women, 62 years; men, 42 years), with a median follow-up time of 33.5 months (range, 10-40 months), were treated. All patients presented with detectable SLNs. In 7 cases, the SLN(s) and the residual ND were negative for CM. In 3 cases, the SLN(s) were positive without further CM in the other neck nodes. Furthermore, 1 patient showed additional CMs after 10 months in the contralateral neck and lung metastasis after 18 months, but none at the time of the initial treatment. The concept of an SNB appears to be applicable to the management of the cNO neck in small SCC of the tongue. The role of SNB in the management of SCC requires further investigation by prospective trials with larger patient numbers.
\end{abstract}

Correspondence to: Dr Keyvan Sagheb, Department of Oral and Maxillofacial Surgery-Plastic Surgery, University Medical Center, Johannes Gutenberg-University of Mainz, Augustusplatz 2, Mainz 55131, Germany

E-mail: keyvan.sagheb@unimedizin-mainz.de

Key words: cervical metastases, oral cancer, squamous cell carcinoma of the tongue, sentinel lymph node

\section{Introduction}

Oral cancer is responsible for 200,000-350,000 cancer-associated fatalities per year worldwide and is thus ranked sixth with regard to the cause of mortality due to tumors $(1,2)$.

Beside the time of diagnosis and the consequent size of the tumor (3), the presence of lymph node metastasis in the neck is the most important prognostic indicator $(4,5)$. Oral SCC is disseminated preferentially by the lymphatic system and mainly the cervical lymph nodes at levels I and II are affected (6-8). The high incidence of occult cervical lymph node metastases of $25 \%$ in N0 cases in the clinic underscores the clinical significance and the resulting therapeutic difficulties $(9,10)$.

The commonly used staging procedures often cannot predict the absence of CM. Clinical and radiological examination have approximate false-negative and false-positive rates of $30 \%$ in the determination of CM (11). The most precise method and the gold standard for the correct N-staging is the histopathological examination of the surgical specimen following elective neck dissection (END) (12).

The management of the clinically and radiologically negative neck, particularly in patients with early oral SCC, remains a matter of debate, although the majority of centers favor END for staging of the neck and the removal of occult disease (11).

In the modern surgical treatment of melanoma or breast cancer, the presence of regional lymph node metastases is evaluated by the identification and examination of the sentinel lymph node (SLN). Radiolabeled colloid solution is injected around the primary tumor, which drains to the next lymph nodes and predominantly to the SLN, which may contain metastatic deposits of the primary tumor. The combination of pre-operative lymphoscintigraphy and the intraoperative detection of the SLN with a $\gamma$-probe allows the radioactive tracer in the lymph nodes to be precisely located during the surgery $(11,13)$.

In the past decade, the SLN-technique has been increasingly used for other malignancies, including head and neck carcinomas. Technical developments and a gain in experience have led to a wider use of SNB, even in the complex lymphatic system of the head and neck region (14). Multiple small patient series have been published evaluating the application of SLN biopsy for head and neck cancers, with a sensitivity of at least $75 \%$ for the identification of CM (Table I) $(11,15,16)$. But the 
Table I. Epidemiological and clinical data.

\begin{tabular}{|c|c|c|c|c|c|c|c|}
\hline Patient & Gender & $\begin{array}{l}\text { Age, } \\
\text { years }\end{array}$ & $\begin{array}{l}\text { Risk } \\
\text { factors }\end{array}$ & $\begin{array}{c}\text { No. of SLNs } \\
\text { detected during surgery }\end{array}$ & $\begin{array}{l}\text { No. of } \\
\text { CMs }\end{array}$ & $\begin{array}{l}\text { Follow-up } \\
\text { time, months }\end{array}$ & Relapse \\
\hline 1 & Male & 21 & No & 2 & 0 & 33 & No \\
\hline 2 & Male & 28 & Yes & 2 & 0 & 39 & No \\
\hline 3 & Male & 32 & No & 4 & 1 & 18 & After 10 months \\
\hline 4 & Female & 33 & Yes & 2 & 0 & 22 & No \\
\hline 5 & Female & 59 & Yes & 2 & 1 & 28 & No \\
\hline 6 & Male & 62 & Yes & 3 & 2 & 40 & No \\
\hline 7 & Female & 63 & No & 2 & 0 & 38 & No \\
\hline 8 & Male & 69 & Yes & 2 & 0 & 40 & No \\
\hline 9 & Female & 75 & Yes & 3 & 0 & 10 & No \\
\hline 10 & Female & 82 & Yes & 2 & 0 & 34 & No \\
\hline
\end{tabular}

SLN, sentinel lymph node; CM, cervical metastases.

Table II. pTNM classification following surgical therapy.

\begin{tabular}{lc}
\hline pTNM stage & Patients, $\mathrm{n}(\%)$ \\
\hline T-Stage & \\
pT1 & $8(80)$ \\
pT2 & $2(20)$ \\
N-stage & \\
pN0 & $7(70)$ \\
pN1 & $2(20)$ \\
pN2 & $1(10)$ \\
M-stage & \\
cM0 & $10(100)$ \\
Grade & \\
G1 & $4(40)$ \\
G2 & $5(50)$ \\
G3 & $1(10)$ \\
\hline
\end{tabular}

pTNM, pathological tumor-node-metastasis.

majority of these studies included higher stage SCC and did not focus on a specific region and a clinical N0 neck.

The aim of the present study was to analyze and evaluate the applicability of the SLN concept for T1/T2 SCC of the tongue with a clinical NO situation.

\section{Patients and methods}

Patients. Between 2010 and 2012, 10 patients with SCC of the tongue were selected from the Department of Oral and Maxillofacial of the University Medical Center (Johannes Gutenberg-University of Mainz, Mainz, Germany) to take part in the study. The criteria for inclusion were: SCC of the tongue, a tumor size $<\mathrm{T} 3$ and a clinical N0 situation. All tumors were classified and staged according to the 2003 tumor-node-metastasis (TNM) staging system of the Union for International Cancer Control, and special attention was paid to the CM (17).
The study protocol was approved by the internal institutional review board and informed consent was obtained from all the patients involved in the study. Computed tomography and ultrasonography of the head and neck region were performed on all patients prior to the treatment.

Treatment. All patients received peritumorous injections of technetium-99m-labeled colloidal human serum albumin $(0.2 \mathrm{ml} ; 50 \mathrm{MBq})$ in an attempt to completely surround the tumor in its deep and lateral aspects. Injection was performed 1 day prior to surgery. The pre-operative lymphoscintigraphy was performed $30 \mathrm{~min}$ after the injection. Static images were accomplished in lateral and antero-posterior projections, and the radioactive lymph nodes were marked on the skin and controlled by B-mode sonography.

Beside the resection of the tongue tumor, all patients received an END at levels I-III. Using a hand-held $\gamma$-probe (Gamma Finder ${ }^{\circledR}$ II, World Of Medicine USA, Inc., Orlando, Florida, USA), the SLN was identified in vivo and dissected separately. Next, the remaining neck was re-evaluated for the absence of radioactivity. All lymph nodes with radioactivity were dissected and considered as SLNs. Afterwards, the proposed END was performed. The SLNs and all neck specimens from the subsequent END were sent for histopathological examination.

\section{Results}

The cohort consisted of $5(50 \%)$ female and $5(50 \%)$ male patients, with an average age of 52 years and a range of 21-82 years (female: Mean, 62 years; range, 33-82 years; male: Mean, 42 years; range, 21-69 years). The majority of the patients $(70 \%)$ showed a risk profile regarding smoking and alcohol consumption (Table I).

SCC was evenly spread in the tongue without a preference for a side, however, $70 \%$ was located in the front and middle section of the tongue (Fig. 1).

The pathological TNM stage of the patients is shown in Table II; $80 \%$ of the patients presented with a T1 tumor and $20 \%$ with a T2 tumor. No distant metastases were detected 


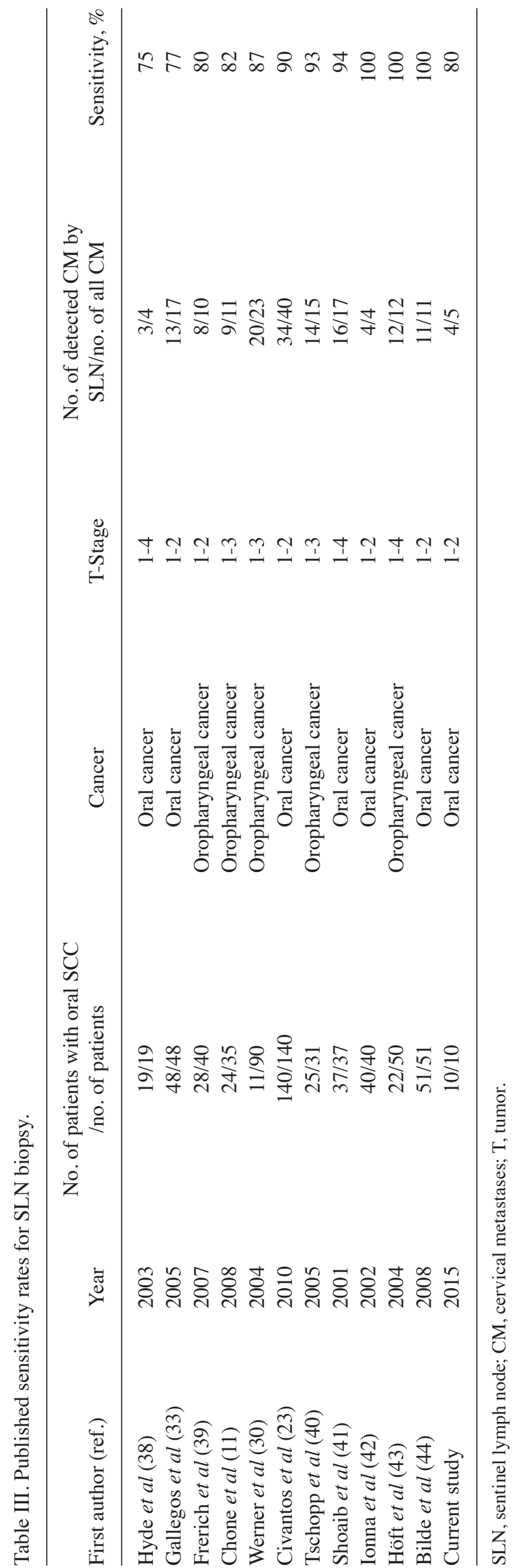

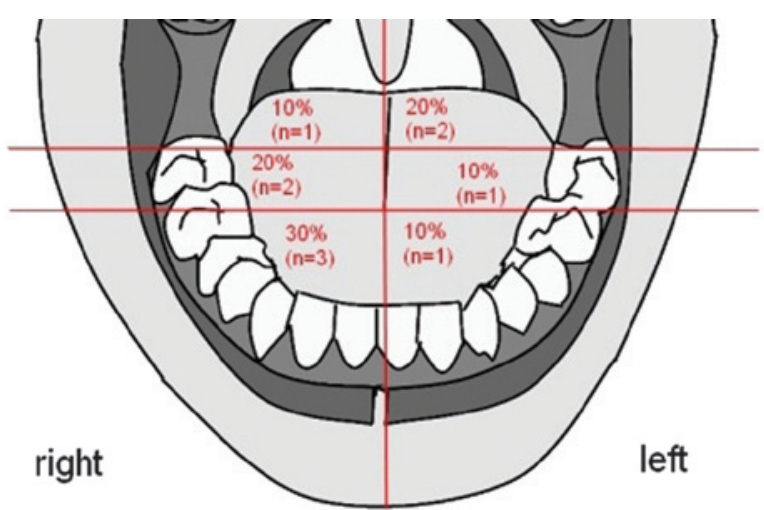

Figure 1. Classification and distribution of the primary tumor location.

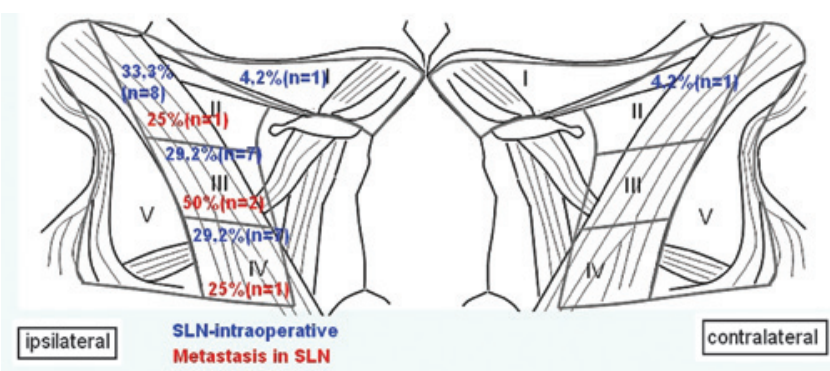

Figure 2. Distribution of the sentinel lymph nodes (SLNs) detected during the surgery (blue) and distribution of the cervical metastases following pathological examination according to the neck level (red).

following primary staging. The majority of the patients (90\%) presented with a tumor of grade G1-G2.

In all patients, SLN could be detected intraoperatively. On average, 2.4 SLNs per patient were found. Fig. 2 shows the distribution of SLNs and CMs at the neck level. A total of 2 SLNs were found in 7 patients, 3 SLNs in 2 patients and $1 \mathrm{SLN}$ in 1 patient were detected. In 7 cases, the SLNs and the residual neck dissection were negative for cervical lymph node metastasis.

In total, $30 \%(\mathrm{n}=3)$ of the patients exhibited lymph node metastases, which were detected by the SLN biopsy, without further CM in the other neck nodes. One patient exhibited skip metastasis; the patient presented with a CM in a SLN at level IV, which had bypassed the common upper neck level I-III.

Additional CMs were developed in 1 patient after 10 months in the contralateral neck, with lung metastasis after 18 months.

The median follow-up time for the patients was 32 months (range, 8-39 months). During the follow-up, none of the other 9 patients experienced local or cervical recurrence.

If the case with the contralateral CM recurrence after 10 months is defined as a false-negative result, then the sensitivity and specificity of the SLN biopsy in the patient group were $75 \%$ (3/4 patients with $\mathrm{CM}$ were detected) and $100 \%$ (6/6 patient without $\mathrm{CN}$ were detected), respectively, and the false negative rate was $25 \%$.

\section{Discussion}

The demographic data of the present SCC patients, with a mean age of 52 years and the high presence of risk factors, are comparable with the international literature (15-20). SCC was 
evenly spread in the tongue and was identical to the distribution pattern in the literature (21).

The management of patients with early oral SCC with a clinically negative neck remains controversial. The majority of clinics prefer the END instead of a wait-and-see strategy due to the high rate of occult metastases. However, 70-80\% of this patient group are ultimately $\mathrm{pN} 0$ and are theoretically overtreated with a selective neck dissection (SND) $(22,23)$. Although an SND is less invasive than a modified radical dissection, measurable morbidity does exist, including shoulder dysfunction, contour changes, pain and lower lip paresis (24-27). Although the SND has proven reliability and worldwide acceptance, it is an extended surgery compared with the SLN biopsy, meaning a longer surgical time, higher costs and greater morbidity. Functional outcome and post-operative complications following an SLN biopsy are also significantly better than after an SND $(28,29)$.

The concept of an SLN biopsy provides the possibility of accurate pathological cervical node staging, whilst minimizing the invasiveness of the procedure and its associated morbidity. In addition, pre-operative lymphoscintigraphy and intraoperative detection with a hand-held $\gamma$-probe have the additional advantage of identifying aberrant drainage pathways $(22,23)$. In the present study, a contralateral SLN could be detected in 1 patient and a CM was found at level IV, which had bypassed the common upper neck level I-III (skip metastasis).

The SLN biopsy has the benefit of concentrating only on the relevant nodes for pathological examination. This selection allows a more in-depth evaluation of the small number of sentinel nodes, using step serial sections and immunohistochemistry $(22,30,31)$. However, if there are multiple SLNS at different levels, the number of SLNs that should be removed for the examination remains unknown. The majority of studies recommend the removal of at least 2-3 SLNs to reduce the possibility of false-negative results (32-34). In the present study, an average of 2.4 SLNs were detected per patient.

There are a number of studies focusing on the use of SLN in SCC (Table III) $(11,15,16,26,33,36,38-44)$. But only few studies do have a homogenous clientele with only small tumors and a clinical NO neck in which the SLN is of importance. In addition the majority of these studies did not focus on a specific region (oral cavity vs. oropharynx). The sensitivity of the SLN biopsy for head and neck cancer varies in the literature between 75 and $100 \%$.

The sensitivity of the SLN biopsy for head and neck cancer varies in the literature between 75 and $100 \%$. This has to be compared with the rate of regional recurrence after SND, which is recorded as between $6-30 \%$ in the literature (35-37). In the present patient group, the sensitivity of the SLN biopsy was $75 \%$ when defining the contralateral CM recurrence after 10 months in 1 patient as a false-negative result.

Although further studies are necessary to confirm the results, patients with cNO and early-stage oral SCC may benefit from an SLN biopsy by avoiding the morbidity of a neck dissection.

\section{References}

1. Argiris A, Karamouzis MV, Raben D and Ferris RL: Head and neck cancer. Lancet 371: 1695-1709, 2008.

2. Jemal A, Siegel R, Ward E, et al: Cancer statistics, 2008. CA Cancer J Clin 58: 71-96, 2008.
3. Kowalski LP and Carvalho AL: Influence of time delay and clinical upstaging in the prognosis of head and neck cancer. Oral Oncol 37: 94-98, 2001.

4. Capote A,Escorial V,Muñoz-Guerra MF, Rodriguez-Campo FJ, Gamallo C and Naval L: Elective neck dissection in early-stage oral squamous cell carcinoma-does it influence recurrence and survival? Head Neck 29: 3-11, 2007.

5. Hiratsuka H, Miyakawa A, Nakamori K, Kido Y, Sunakawa $H$ and Kohama G: Multivariate analysis of occult lymph node metastasis as a prognostic indicator for patients with squamous cell carcinoma of the oral cavity. Cancer 80: 351-356, 1997.

6. Kowalski LP, Bagietto R, Lara JR, Santos RL, Tagawa EK and Santos IR: Factors influencing contralateral lymph node metastasis from oral carcinoma. Head Neck 21: 104-110, 1999.

7. Pimenta Amaral TM, Da Silva Freire AR, Carvalho AL, Pinto CA and Kowalski LP: Predictive factors of occult metastasis and prognosis of clinical stages I and II squamous cell carcinoma of the tongue and floor of the mouth. Oral Oncol 40: 780-786, 2004.

8. Woolgar JA: The topography of cervical lymph node metastases revisited: the histological findings in 526 sides of neck dissection from 439 previously untreated patients. Int $\mathbf{J}$ Oral Maxillofac Surg 36: 219-225, 2007.

9. Mishra P and Sharma AK: A 3-year study of supraomohyoid neck dissection and modified radical neck dissection type I in oral cancer: with special reference to involvement of level IV node metastasis. Eur Arch Otorhinolaryngol 267: 933-938, 2010.

10. Yuen AP, Ho CM, Chow TL, Tang LC, Cheung WY, Ng RW, Wei WI, Kong CK, Book KS, Yuen WC, et al: Prospective randomized study of selective neck dissection versus observation for N0 neck of early tongue carcinoma. Head Neck 31: 765-772, 2009.

11. Chone CT, Magalhes RS, Etchehebere E, Camargo E, Altemani A and Crespo AN: Predictive value of sentinel node biopsy in head and neck cancer. Acta Otolaryngol 128: 920-924, 2008.

12. Woolgar JA, Beirne JC, Vaughan ED, Lewis-Jones HG, Scott J and Brown JS: Correlation of histopathologic findings with clinical and radiologic assessments of cervical lymph-node metastases in oral cancer. Int J Oral Maxillofac Surg 24: 30-37, 1995.

13. Stoeckli SJ, Alkureishi LW and Ross GL: Sentinel node biopsy for early oral and oropharyngeal squamous cell carcinoma. Eur Arch Otorhinolaryngol 266: 787-793, 2009.

14. Kuriakose MA and Trivedi NP: Sentinel node biopsy in head and neck squamous cell carcinoma. Curr Opin Otolaryngol Head Neck Surg 17: 100-110, 2009.

15. Bertz J, Dahm S, Haberland J, Kraywinkel K, Kurth BM and Wolf U: Spread of cancers in Germany. Development of prevalence between 1990 and 2010. A publication of the Centre for Cancer Registry Data at the RKI, Westkreuz-Druckerei, Berlin, 2010. Robert Koch Institute, Berlin, 2010.

16. Mashberg A, Boffetta P, Winkelman R and Garfinkel L: Tobacco smoking, alcohol drinking and cancer of the oral cavity and oropharynx among U.S. veterans. Cancer 72: 1369-1375, 1993.

17. Blot WJ, McLaughlin JK, Winn DM, et al: Smoking and drinking in relation to oral and pharyngeal cancer. Cancer Res 48: 3282-3287, 1988

18. Hashibe M, Brennan P, Benhamou S, et al: Alcohol drinking in never users of tobacco, cigarette smoking in never drinkers and the risk of head and neck cancer: pooled analysis in the international head and neck cancer epidemiology consortium. J Natl Cancer Inst 99: 777-789, 2007.

19. Maier H, Tisch M, Conradt C and Pötschke-Langer M: Alcohol drinking and cancer of the upper aerodigestive tract in women. Dtsch Med Wochenschr 124: 851-854, 1999.

20. Petti S: Lifestyle risk factors for oral cancer. Oral Oncol 45: 340-350, 2009

21. Cooper JS, Porter K, Mallin K, et al: National Cancer Database report on cancer of the head and neck: 10-year update. Head Neck 31: 748-758, 2009.

22. Alkureishi LW, Ross GL, Shoaib T, et al: Sentinel node biopsy in head and neck squamous cell cancer: 5-year follow-up of a European multicenter trial. Ann Surg Oncol 17: 2459-2464, 2010.

23. Civantos FJ, Zitsch RP, Schuller DE, Agrawal A, Smith RB, Nason R, Petruzelli G, Gourin CG, Wong RJ, Ferris RL, et al: Sentinel lymph node biopsy accurately stages the regional lymph nodes for T1-T2 oral squamous cell carcinomas: Results of a prospective multi-institutional trial. J Clin Oncol 28: 1395-1400, 2010. 
24. Chepeha DB, Taylor RJ, Chepeha JC, Teknos TN, Bradford CR, Sharma PK, Terrell JE and Wolf GT: Functional assessment using constant's shoulder scale after modified radical and selective neck dissection. Head Neck 24: 432-436, 2002.

25. Nibu K, Ebihara Y, Ebihara M, Kawabata K, Onitsuka T, Fujii T and Saikawa M: Quality of life after neck dissection: A multicenter longitudinal study by the japanese clinical study group on standardization of treatment for lymph node metastasis of head and neck cancer. Int J Clin Oncol 15: 33-38, 2010.

26. Terrell JE, Ronis DL, Fowler KE, Bradford CR, Chepeha DB Prince ME, Teknos TN, Wolf GT and Duffy SA: Clinical predictors of quality of life in patients with head and neck cancer. Arch Otolaryngol Head Neck Surg 130: 401-408, 2004.

27. Ferlito A, Rinaldo A, Silver CE, Gourin CG, Shah JP, Clayman GL, Kowalski LP, Shaha AR, Robbins KT, Suárez C, et al: Elective and therapeutic selective neck dissection. Oral Oncol 42: 14-25, 2006.

28. Murer K, Huber GF, Haile SR and Stoeckli SJ: Comparison of morbidity between sentinel node biopsy and elective neck dissection for treatment of the $n 0$ neck in patients with oral squamous cell carcinoma. Head Neck 33: 1260-1264, 2011.

29. Schiefke F, Akdemir M, Weber A, Akdemir D, Singer S and Frerich B: Function, postoperative morbidity and quality of life after cervical sentinel node biopsy and after selective neck dissection. Head Neck 31: 503-512, 2009.

30. Werner JA, Dünne AA, Ramaswamy A, Dalchow C, Behr T, Moll R, Folz BJ and Davis RK: The sentinel node concept in head and neck cancer: Solution for the controversies in the N0 neck? Head Neck 26: 603-611, 2004.

31. Ambrosch P and Brinck U: Detection of nodal micrometastases in head and neck cancer by serial sectioning and immunostaining. Oncology (Williston Park) 10: 1221-1226; discussion 1226, 1229, 1996.

32. Antonio JK, Santini S, Politi D, Sulfaro S, Spaziante R, Alberti A, Pin $M$ and Barzan L: Sentinel lymph node biopsy in squamous cell carcinoma of the head and neck: 10 years of experience. Acta Otorhinolaryngol Ital 32: 18-25, 2012.

33. Gallegos-Hernández JF, Hernández-Hernández DM,Flores-Díaz R, Sierra-Santiesteban I, Pichardo-Romero P, Arias-Ceballos H, Minauro-Muñoz G and Alvarado-Cabrero I: The number of sentinel nodes identified as prognostic factor in oral epidermoid cancer. Oral Oncol 41: 947-952, 2005.

34. Atula T, Shoaib T, Ross GL, Gray HW and Soutar DS: How many sentinel nodes should be harvested in oral squamous cell carcinoma? Eur Arch Otorhinolaryngol 265 (Suppl 1): S19-S23, 2008.
35. Fasunla AJ, Greene BH, Timmesfeld N, Wiegand S, Werner JA and Sesterhenn AM: A meta-analysis of the randomized controlled trials on elective neck dissection versus therapeutic neck dissection in oral cavity cancers with clinically node-negative neck. Oral Oncol 47: 320-324, 2011.

36. Liu TR, Chen FJ, Yang AK, Zhang GP, Song M, Liu WW, Chen WC, Chen YF, Ouyang D and Li QL: Elective neck dissection in clinical stage I squamous cell carcinoma of the tongue: Does it improve regional control or survival time? Oral Oncol 47: 136-141, 2011.

37. Ebrahimi A, Ashford BG and Clark JR: Improved survival with elective neck dissection in thick early-stage oral squamous cell carcinoma. Head Neck 34: 709-716, 2012.

38. Hyde NC, Prvulovich E, Newman L, Waddington WA, Visvikis D and Ell P: A new approach to pre-treatment assessment of the N0 neck in oral squamous cell carcinoma: The role of sentinel node biopsy and positron emission tomography. Oral Oncol 39: 350-360, 2003.

39. Frerich B, Förster M, Schiefke F, Wittekind C, Hemprich A and Sabri O: Sentinel lymph node biopsy in squamous cell carcinomas of the lips and the oral cavity-a single center experience. J Surg Oncol 95: 97-105, 2007.

40. Tschopp L, Nuyens M, Stauffer E, Krause T and Zbären P: The value of frozen section analysis of the sentinel lymph node in clinically N0 squamous cell carcinoma of the oral cavity and oropharynx. Otolaryngol Head Neck Surg 132: 99-102, 2005.

41. Shoaib T, Soutar DS, MacDonald DG, Camilleri IG, Dunaway DJ, Gray HW, McCurrach GM, Bessent RG, MacLeod TI and Robertson AG: The accuracy of head and neck carcinoma sentinel lymph node biopsy in the clinically N0 neck. Cancer 91: 2077-2083, 2001.

42. Ionna F, Chiesa F, Longo F, Manola M, Villano S, Calabrese L, Lastoria S and Mozzillo N: Prognostic value of sentinel node in oral cancer. Tumori 88 (Suppl 1): S18-S19, 2002.

43. Höft S, Maune S, Muhle C, Brenner W, Czech N, Kampen WU, Jänig U, Laudien M, Gottschlich S and Ambrosch P: Sentinel lymph-node biopsy in head and neck cancer. Br J Cancer 91: 124-128, 2004.

44. Bilde A, von Buchwald C, Therkildsen MH, Mortensen J, Kirkegaard J, Charabi B and Specht L: Need for intensive histopathologic analysis to determine lymph node metastases when using sentinel node biopsy in oral cancer. Laryngoscope 118: 408-414, 2008 